\title{
Where and When Bacterial Chromosome Replication Starts: A Single Cell Perspective
}

Damian Trojanowskit, Joanna Hołówka ${ }^{\dagger}$ and Jolanta Zakrzewska-Czerwińska ${ }^{* t}$

Department of Molecular Microbiology, Faculty of Biotechnology, University of Wrocław, Wrocław, Poland

Bacterial chromosomes have a single, unique replication origin (named oriC), from which DNA synthesis starts. This study describes methods of visualizing oriC regions and the chromosome replication in single living bacterial cells in real-time. This review also discusses the impact of live cell imaging techniques on understanding of chromosome replication dynamics, particularly at the initiation step, in different species of bacteria.

Keywords: replication initiation, oriC, replisome, single-cell, bacterial chromosome

OPEN ACCESS

Edited by:

Feng Gao,

Tianjin University, China

Reviewed by:

Julia Grimwade,

Florida Institute of Technology,

United States

Christian J. Rudolph,

Brunel University London,

United Kingdom

*Correspondence:

Jolanta Zakrzewska-Czerwińska jolanta.zakrzewska@uni.wroc.pl

tThese authors have contributed equally to this work

Specialty section:

This article was submitted to

Evolutionary and Genomic

Microbiology,

a section of the journal

Frontiers in Microbiology

Received: 30 September 2018 Accepted: 02 November 2018 Published: 26 November 2018

Citation:

Trojanowski D, Hołówka J and Zakrzewska-Czerwińska J (2018) Where and When Bacterial Chromosome Replication Starts:

A Single Cell Perspective.

Front. Microbiol. 9:2819.

doi: 10.3389/fmicb.2018.02819

\section{INTRODUCTION}

DNA replication is an enormously intricate process, in which a few dozen enzymes catalyze a series of reactions, including DNA unwinding and the synthesis of sister DNA strands. This process must be highly precise and accurately timed to prevent any unnecessary loss of energy and to ensure that DNA is faithfully and completely replicated only once per cell-division cycle (Leonard and Grimwade, 2015). In all three domains of life, chromosomal replication is mainly regulated at the initiation step (Nielsen and Løbner-Olesen, 2008; Aves, 2009; Skarstad and Katayama, 2013), an important cell cycle checkpoint guaranteeing that DNA replication begins at the right place and time.

Most bacterial genomes consist of one covalently closed chromosome (Figure 1). In a few bacteria, however, the genetic information is distributed on two [e.g., Vibrio cholerae (Trucksis et al., 1998)] or even more [e.g., Paracoccus denitrificans (Winterstein and Ludwig, 1998)] chromosomes. Interestingly, some bacteria possess linear chromosomes [e.g., Streptomyces (Lin et al., 1993)].

In contrast to eukaryotes, bacterial chromosomes have a single, unique origin of replication (oriC) (Bird et al., 1972; Kaguni and Kornberg, 1984; Gao and Zhang, 2008; Masai et al., 2010; Méchali, 2010; Katayama, 2017). DNA synthesis is initiated at this unique oriC, generating a single replication eye per chromosome (Figure 1). Cooperative binding of the initiator protein, DnaA, to multiple DnaA-recognition sites (DnaA boxes) within the oriC region triggers separation of the DNA strands at the DNA unwinding element (DUE), providing an entry site for the machinery of replication (replisome, Figures 1, 2A; Skarstad et al., 1986, 1990; Bach et al., 2008; Leonard and Grimwade, 2011; Wolański et al., 2014; Richardson et al., 2016).

Enormous progress has been made in recent years toward understanding the mechanisms of replication initiation, particularly the organization and function of oriC regions in different bacteria (Donczew et al., 2012; Makowski et al., 2016; Jaworski et al., 2018; Midgley-Smith et al., 2018; Samadpour and Merrikh, 2018). Less is known, however, about the subcellular localization of replication processes during the cell cycle in various bacterial species. The development of sophisticated cell biology techniques has allowed examination of when and where the replication machinery is assembled within the bacterial cells, and how the initiation of replication is coordinated with the cell cycle (Donczew et al., 2012; Harms et al., 2013; Santi and McKinney, 2015; 


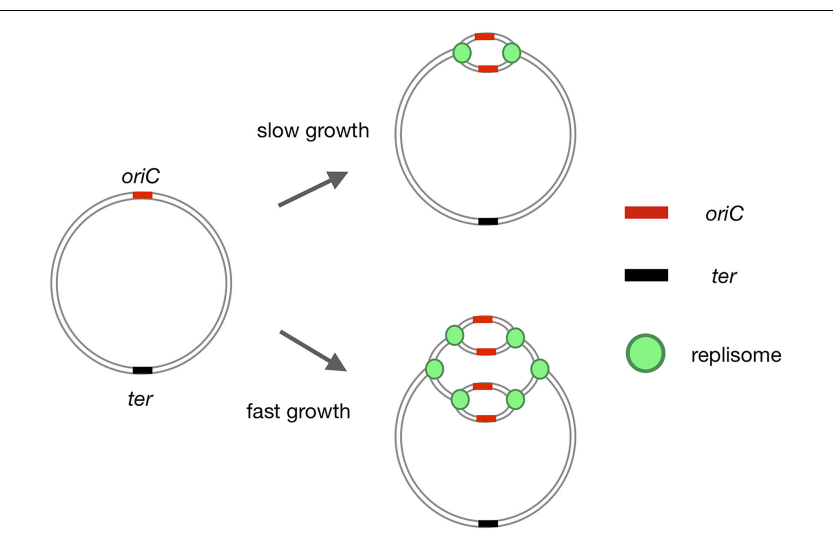

FIGURE 1 | Initiation of bacterial replication. Replication of the bacterial chromosome is initiated at a single oriC region, proceeds in both directions, and terminates at the ter region. During slow growth, replication is initiated once per cell cycle. In fast growers under optimal conditions, another round of replication is initiated before the previous round has been completed, resulting in the inheritance by daughter cells of partially replicated chromosomes.

Trojanowski et al., 2015; Böhm et al., 2017). This process is particularly interesting in bacteria with two chromosomes (V. cholerae) (Demarre et al., 2014; Ramachandran et al., 2018) and in those that undergo complex cell differentiation (Caulobacter crescentus) (Jensen et al., 2001; Toro et al., 2008) and/or exhibit complicated life cycles, e.g., Myxococcus xanthus (Harms et al., 2013; Lin et al., 2017) and Streptomyces species (Kois-Ostrowska et al., 2016). In these bacteria, the regulatory networks that control replication initiation are likely to be intricate and require specific mechanisms that can synchronize the initiation of chromosomal replication with developmental processes.

The main goal of this review is to highlight imaging techniques that allow the determination of the subcellular location of oriC regions and the initiation of chromosome replication (i.e., assembly of the replication machinery) in single living bacterial cells in real time. This review also discusses the impact of real-time single-cell imaging on understanding of chromosome replication dynamics, particularly at the initiation step, in different bacteria.

\section{VISUALIZATION OF REPLICATION INITIATION AND REPLISOME DYNAMICS IN LIVE CELLS}

The development of live cell imaging techniques has allowed the visualization of replisomes (Figure 2A; Jensen et al., 2001; ReyesLamothe et al., 2008; Wang and Sherratt, 2010; Harms et al., 2013; Santi and McKinney, 2015; Trojanowski et al., 2015; Mangiameli et al., 2017) in live cells and the study of DNA replication dynamics, including the timing and localization of replication initiation, in real time at the single-cell level. Microscopic analysis of live cells has several advantages over analysis of fixed samples. Fixing the cells, a process that involves dehydration and/or intracellular cross-linking, may influence the localization of proteins or subcellular structures of interest. Moreover, some fusions with fluorescent proteins (FP) are sensitive to the harsh conditions used during fixation. For example, different sample preparation of Mycobacterium smegmatis cells results in ParAEGFP localizing either apically or as a cloud arising from the new cell pole (Ginda et al., 2013, 2017). Furthermore, permeabilization of the bacterial cell wall during immunostaining may contribute to a loss of cytoplasmic content or, due to cellular crowding, may generate high background noise or alter the localization of large immunocomplexes, particularly when using secondary antibodies for signal amplification. Although several high quality studies of fixed samples have provided invaluable data, the conditions found in cells fixed on a coverslip only approximate the conditions found in live cells.

Replication is visualized primarily by the fusion of different replisome (DNA polymerase III) subunits (Figure 2A) to a variety of FP. The choice of subunit to create the fusion protein should be guided by the specific application and the specific type of bacterium. Escherichia coli is the best characterized bacterial model for tracking live replication (Kongsuwan et al., 2002; Bates and Kleckner, 2005; Fossum et al., 2007; ReyesLamothe et al., 2008, 2010; Su'etsugu and Errington, 2011; Wang et al., 2011; Moolman et al., 2014; Beattie et al., 2017). However, several reports have tracked replication in other organisms, including Bacillus subtilis (Lemon and Grossman, 1998; Migocki et al., 2004; Berkmen and Grossman, 2006; Mangiameli et al., 2017; Li et al., 2018), C. crescentus (Jensen et al., 2001; Fernandez-Fernandez et al., 2013; Arias-Cartin et al., 2017), V. cholerae (Srivastava and Chattoraj, 2007; Stokke et al., 2011), M. smegmatis (Santi et al., 2013; Santi and McKinney, 2015; Trojanowski et al., 2015, 2017), Streptomyces coelicolor (RubanOśmiałowska et al., 2006; Wolański et al., 2011), Corynebacterium glutamicum (Böhm et al., 2017), Pseudomonas aeruginosa (ValletGely and Boccard, 2013), M. xanthus (Harms et al., 2013), and Streptococcus pneumoniae (Raaphorst et al., 2017). Findings of these studies may help in the construction of fluorescent fusions of replisome components in other bacteria. It is also important to consider alternative $\mathrm{N}$ - and C-terminal fusion, as one, or sometimes both, ends of target proteins may be implicated in inter- or intra-molecular interactions. The sliding clamp (Figure 2A) is the protein of choice in most studies and both $\mathrm{N}$ - and C-terminal fusions proved to be functional in a range of species (Kongsuwan et al., 2002; Reyes-Lamothe et al., 2010; Su'etsugu and Errington, 2011; Moolman et al., 2014; Santi and McKinney, 2015; Trojanowski et al., 2015; Arias-Cartin et al., 2017; Böhm et al., 2017; Mangiameli et al., 2017; Hołówka et al., 2018). However, the sliding clamp also participates in processes other than DNA replication, including recombination and DNA repair, possibly altering the distribution of DnaN-FP (or FP-DnaN) foci in these cells. This is not usually a concern in wild-type-like fluorescent reporter strains, under both optimal and minimal conditions, but may be of concern in knock-out/overproducing mutant strains, involving, for example, genes engaged in DNA repair, or when studying replication dynamics under stress-inducing conditions such as in the presence of antibiotics, mutagenic compounds like 
A

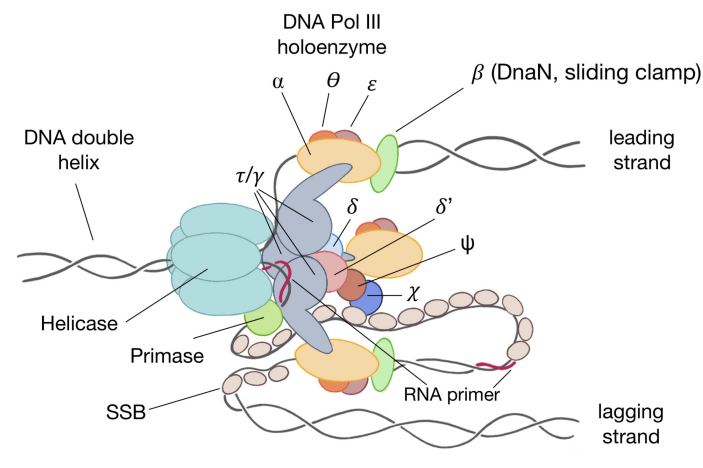

B

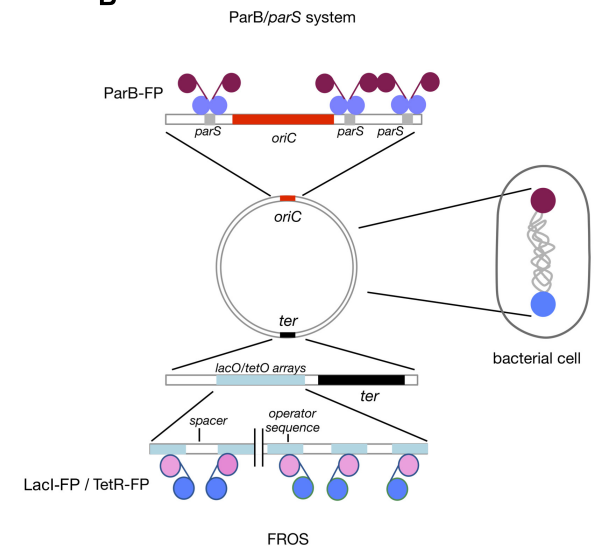

FIGURE 2 | Replisome structure and localization. (A) Schematic diagram of a replisome. A replisome is a multiprotein complex involved in DNA replication. A helicase unwinds the chromosome, separating the two single-stranded DNA strands. The leading strand is synthesized continuously, while the lagging strand is synthesized in approximately $1 \mathrm{kbp}$ fragments, starting from the short primers added by the primase. The three core polymerases are loaded into each replication fork by the clamp loader and bind to the sliding clamp, enabling high activity of the entire replisome. (B) Schematic localization of chromosomal loci using ParB/parS and FROS system. Under optimal conditions (a bacterial cell with a longitudinal chromosome conformation), ParB-FP binds to parS sequences (purple) in the oriC region, while the ter region (blue) is labeled through insertion of operator arrays and subsequent binding of repressor-FP.

mitomycin, and replication inhibitors. In these experiments, choosing another replisome component may be advisable. Beside the siding clamp, DnaX (Lemon and Grossman, 2000; Bates and Kleckner, 2005; Berkmen and Grossman, 2006; Vallet-Gely and Boccard, 2013; Raaphorst et al., 2017) (particularly its C-terminal fusion) is frequently used as a replisome localization marker. The dnaX gene encodes two alternative proteins, $\tau$ - the full-length protein encoded by the dnaX gene, and $\gamma$, which originates from ribosome switching during translation, resulting in premature termination of translation and generating a truncated protein. Single-stranded DNA binding protein (SSB) (Figure 2A) has also been tested in several studies (ReyesLamothe et al., 2008, 2010; Harms et al., 2013; Sukumar et al., 2014; Santi and McKinney, 2015; Mangiameli et al., 2017; Raaphorst et al., 2017). Monitoring replisome dynamics in strains expressing fusion proteins encoded on an episomal plasmid is not recommended, as plasmid replication is triggered mainly by the same protein components that trigger chromosomal replication. Fusion with catalytic core subunits (Lemon and Grossman, 1998; Migocki et al., 2004; Trojanowski et al., 2017) is also possible, although additional cargo attached to core Pol-DNA III may affect nucleotide incorporation rates and influence the kinetic parameters of the entire replication complex. This was shown for M. smegmatis, where the C-terminal fusion of a catalytic alpha subunit to EYFP prolonged the C-period (Trojanowski et al., 2017). Thus proteins other than the catalytic core complex may be a better choice for studies of replisome dynamics. Other fusions successfully used for replisome tracking include DnaB (DNA helicase) (Jensen et al., 2001; Beattie et al., 2017), DnaQ (ReyesLamothe et al., 2008, 2010; Wallden et al., 2016; Mangiameli et al., 2017), and $\chi$ and $\delta^{\prime}$ subunits (Jensen et al., 2001; ReyesLamothe et al., 2008). When designing a fluorescent fusion for replisome visualization, additional features should be taken into account, especially oligomerization status, fluorescence yield and spectral properties. FP (especially GFP derivatives) are likely to form low-affinity oligomers (Costantini et al., 2012), which may influence the dynamics of the studied protein complex, especially when the fusion protein is produced at a high level. Thus, choosing a fluorescent variant with a lower tendency to undergo oligomerization (e.g., mCherry, mCherry2, mCitrine, and mScarlett) is recommended. Spectral characteristics and brightness are essential, especially when replisomes are localized together with other cellular components (e.g., chromosome and membrane) (Shaner et al., 2005). Importantly, FP are sensitive to $\mathrm{pH}$ and cannot be utilized to analyze anaerobic bacteria, as maturation of the chromophore requires oxygen molecules (Shaner et al., 2005; Landete et al., 2015). Fluorescent fusion proteins are suitable for both qualitative long-term live cell imaging and quantitative analysis. For example, Y-Pet fusion with a variety of replisome subunits was used to quantify the numbers of copies of particular proteins within a replication eye in vivo (Reyes-Lamothe et al., 2010). However, most of these variants lacked the properties required for super-resolution imaging. In the latter case, proteins of interest should be fused with photoactivated or photoconvertible proteins. Recently published studies may provide hints regarding single-molecule resolution microscopy of replication complexes (Georgescu et al., 2012; Stracy et al., 2014; Liao et al., 2016; Lewis et al., 2017). The fusion of replisome subunits with HaloTag may be an alternative to FP. The size of HaloTag is similar to that of FP, but the ligands that bind to HaloTag have better fluorescence yield, resulting in a higher signal compared with standard FPs (HaloTag ${ }^{\circledR}$ Protein Purification System, 2018). The advantage of using direct fluorescent ligands (e.g., dTMR and dR110) is that they do not need to be washed out before acquisition. Halo ligands are also suitable for high-resolution microscopy.

Replication tracking (particularly initiation of replication) is often accompanied by localization of nascent oriCs (Figure 2B). 
The fluorescence repressor operator system (FROS) or ParB/parS is frequently used for live cell tracking (Lau et al., 2003). The FROS system (Figure 2B) consists of two components: operator sequences (usually lacO or tetO arrays repeated up to several hundred times in tandem and interspersed by oligonucleotide spacers) and an FP-tagged repressor protein (LacI-FP or TetRFP), which binds to the operator sequences. FROS was efficiently used to localize chromosomal loci, including oriC, terminus and other specific loci on both replichores in a variety of species (Viollier et al., 2004; Fogel and Waldor, 2005; Frunzke et al., 2008; Liu et al., 2010; Vallet-Gely and Boccard, 2013; Wang et al., 2014; Santi and McKinney, 2015). However, it is often difficult to insert the large operator arrays into the chromosome, particularly in highly transcribed regions such as oriC (Le and Laub, 2014). Moreover, overexpression of repressor may result in replication/transcription hold-up or alteration in segregation of replicated regions (Possoz et al., 2006; Mettrick and Grainge, 2016). Thus, low levels of repressor should be produced, usually by using inducible promoters. Additionally, tracking oriCs together with replisomes requires delivery of the repressor-FP fusion protein from the chromosomal locus, either as a part of an operator array construct or inserted into an attachment site. Although FROS may provide invaluable data, its instability is a major drawback.

The ParB-FP/parS system (which originated from naturally existing chromosome and/or plasmid partitioning strategies) (Figure 2B) represents an easier alternative to FROS. This system uses an intrinsic feature of ParB, its binding to centromerelike parS sequences (Wang et al., 2011; Reyes-Lamothe et al., 2012; Badrinarayanan et al., 2015). Most bacterial species possess the ParABS chromosome segregation system, except for several well-studied Gammaproteobacteria, including E. coli. Because most chromosomal parS sites are localized proximal to the oriC-proximal regions (Livny et al., 2007), introduction of fluorescent ParB, which oligomerizes within parS sequences, addresses all of the system requirements for successful oriC labeling. This approach has been shown effective in a number of bacteria, including Mycobacterium, M. xanthus (Harms et al., 2013), Streptomyces (Donczew et al., 2016; Kois-Ostrowska et al., 2016), C. crescentus (Laloux and Jacobs-Wagner, 2013), and C. glutamicum (Donovan et al., 2010; Böhm et al., 2017). In bacteria lacking a chromosomal ParABS system (e.g., E. coli), plasmid-derived partitioning components (phage P1 or Yersinia pestis MT1ParB/parS systems) are frequently used (Youngren et al., 2000; Li et al., 2002; Nielsen et al., 2006, 2007). The use of plasmid-derived parS/ParB is also beneficial, as it does not interfere with the endogenous chromosomal ParABS system or another plasmid-derived parS/ParB system (P1/MT1), allowing the simultaneous localization of multiple chromosomal loci. Its major advantage compared with FROS is that insertion of only a few copies of parS is sufficient for strong fluorescent signals after ParB-FP binding.

Determination of the specific point (and subcellular localization) at which replication is initiated requires long-term imaging of living cells (from several minutes to hours, depending on the bacterial growth rate and the conditions being tested, e.g., rich versus minimal medium). The simplest way to analyze replication at the single-cell level is to spread the cells of the reporter strain on the agar pad (a thin agar layer between the microscope slide and the cover glass) or on the bottom of solidified medium inside culture dishes (Joyce et al., 2011; Dhar and Manina, 2015). Although simple and low-cost, this approach is not always applicable (e.g., labeling and medium changing). Microfluidic flow chambers are used for the latter purposes, as well as for rapidly changing culture conditions (e.g., applying stress). Various microfluidic chips and plates are commercially available from an increasing number of companies, whereas custom made (usually PDMS) chips are a cost-reducing alternative and also allow for more personalized applications (Wang et al., 2010; Cattoni et al., 2013; Dhar and Manina, 2015; Trojanowski et al., 2015; Wallden et al., 2016). The architecture of microfluidic chips and plates varies among studies and choosing the right one should be dictated by the specific study purpose and the availability of additional equipment, e.g., peristaltic/syringe/pressure pumps, flow controllers, or automation.

\section{SPATIOTEMPORAL LOCALIZATION OF THE REPLISOME DURING REPLICATION INITIATION}

Localization of the replication machinery at the beginning of DNA synthesis is dependent on oriC position, and is therefore connected with the spatial arrangement of the chromosome. In bacteria having oriC and ter regions positioned at the mid-cell, the intervening chromosomal regions (i.e., the left and right chromosomal arms) are stretched out toward opposite cell poles, creating a left-ori-right pattern, whereas cells having oriC and ter regions localized to opposite poles show an ori-ter chromosomal arrangement (Wang and Rudner, 2014). Replisomes in the cells exhibiting a left-ori-right configuration are assembled in the midcell region of the chromosome. This pattern has been observed in E. coli cells (Postow et al., 2004; Valens et al., 2004; Boccard et al., 2005) and during the vegetative growth of B. subtilis (the chromosome in B. subtilis is oscillating between left-ori-right and ori-ter configuration) (Wang et al., 2014; Figure 3A). During sporulation, however, the B. subtilis chromosome adopts an oriter orientation to segregate an entire copy of the chromosome within each spore. Positioning of the oriC at the mid-cell of B. subtilis and E. coli is maintained by the condensins SMC and MukB (a structural homolog of SMC), respectively (Niki et al., 1992; Danilova et al., 2007; Sullivan et al., 2009). SMC can compact large chromosomal regions, and, by interacting with ParB protein, organizes the oriC-proximal regions in $B$. subtilis, with ParB binding to parS sequences located near oriC (Gruber and Errington, 2009). The interaction of MukB with the nucleoid associated protein $\mathrm{HU}$ ensures proper oriC positioning in $E$. coli cells (Lioy et al., 2018). After initiation, E. coli replisomes oscillate near the cell center, while newly replicated oriCs are segregated toward the cell poles (Reyes-Lamothe et al., 2008). In comparison, B. subtilis replisomes colocalize throughout replication (Migocki et al., 2004), and are therefore visible as a single fluorescent focus. Replisome positioning in the cell center can be also found in oval-shaped S. pneumoniae (Kjos and Veening, 2014; van 
A

- oric replisome $\longrightarrow$ chromosome

E. coli

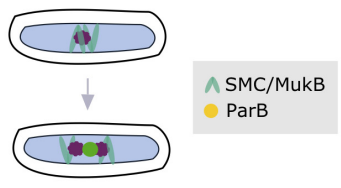

B

M. smegmatis

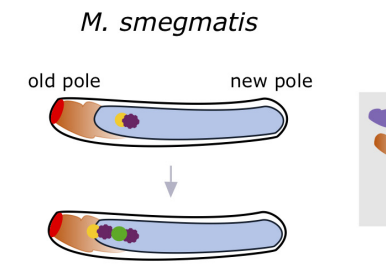

B. subtilis

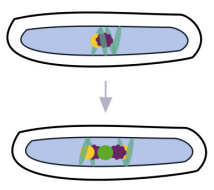

vegetative growth
S. pneumoniae

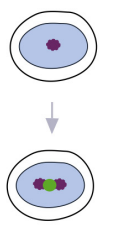

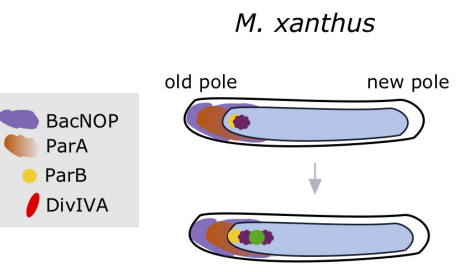

C

C. crescentus

V. cholerae
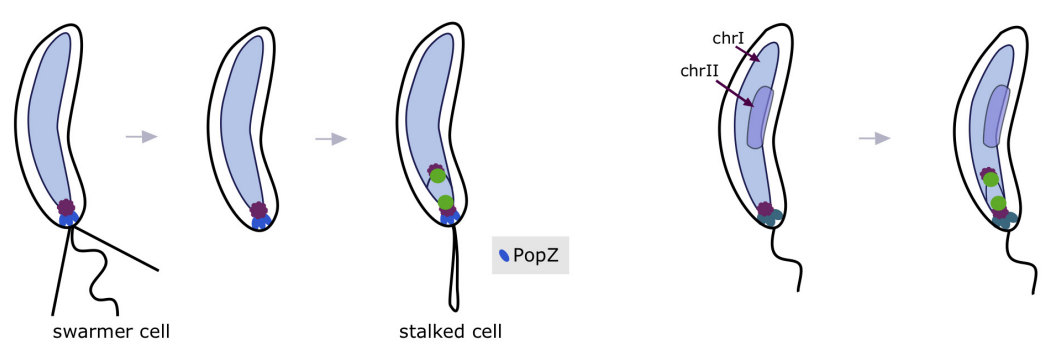

- HubP

D
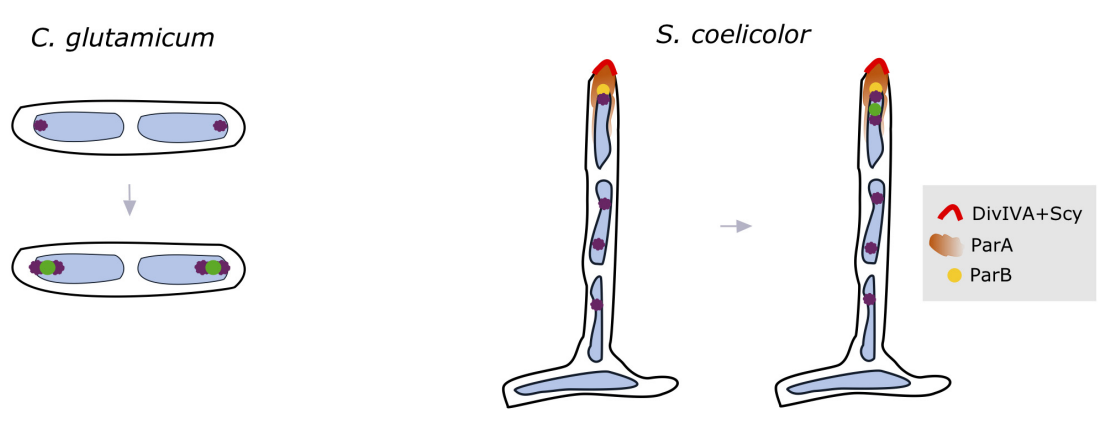

FIGURE 3 | Spatial organization of the chromosome entails positioning of the site of replisome assembly. Bacteria exhibiting a left-ori-right orientation start replication in mid-cell (A), where the oriC region is organized by the condensins SMC/MukB (marked in green) and ParB (indicated as yellow circle). Off-centered replisome positioning (B) is associated with complex interactions between oriC and the ParABS system ( $M$. smegmatis; ParA indicated as orange cloud, ParB in yellow circle and DivIVA in red) or bactofilins (M. xanthus; BacNOP depicted as violet cloud). In the ori-ter organized chromosomes, replication is initiated at the cell pole (C), at which the oriC region is anchored by specific proteins (i.e., PopZ in C. crescentus and HubP in V. cholerae indicated as blue and marine blue ovals, respectively). (D) Subpolar positioning of replisomes has also been observed in the multiploid bacteria S. coelicolor (ParA indicated as orange cloud and polarisome complex proteins: ParB and DivIVA interacting with Scy depicted in yellow and red, respectively) and C. glutamicum. OriC region(s) and replisome(s) are indicated as violet and green circles, while chromosome is depicted in light blue.

Raaphorst et al., 2017), which, similar to many other bacteria including B. subtilis, encodes an SMC homolog.

Some bacteria, such as M. smegmatis (Santi and McKinney, 2015; Trojanowski et al., 2015) and M. xanthus (Harms et al., 2013), exhibit off-center replisome localization during the initiation of replication (see Figure 3B). In M. smegmatis, segregation of the newly replicated oriCs starts immediately after initiation of replication, with one oriC remaining near the old cell pole and the other traveling toward the opposite pole (Ginda et al., 2017; Hołówka et al., 2018). Replisomes oscillate in the 
old-pole-proximal cell half during most of the replication process, but localize closer to the new cell pole prior to termination (Trojanowski et al., 2015). A slight asymmetry in mycobacterial replisome positioning is associated with the apical growth mode of these bacteria. Positioning of oriC region(s) in Mycobacterium depends on the interaction of ParB with ParA protein, which in turn interacts with the polar growth determinant, DivIVA protein (Ginda et al., 2013).

As a result of the asymmetric location of oriC, M. xanthus replisomes are positioned at the subpolar regions (Figure 3B; Harms et al., 2013). Although M. xanthus contains a DivIVA homolog, suggesting analogous interactions at the pole as described for Mycobacterium, deletion of this homolog does not affect cell division or chromosome segregation. Rather, localization of the ParA and ParB-parS complexes (and thus the oriC region) in $M$. xanthus is controlled by the bactofilins BacNOP, through the direct interactions of ParA and ParB with the scaffold created by BacNOP (Lin et al., 2017).

Bacteria exhibiting complex life cycles often show an ori-ter chromosome orientation (Figure 3C). In C. crescentus stalked cells, chromosome replication starts at the old cell pole (Jensen et al., 2001). The anchorage of the chromosome at the old cell pole is maintained by the protein PopZ (Bowman et al., 2008). Similarly, in $V$. cholerae, the origin (oriI) of one of the two chromosomes, chrI, is attached to the old pole by HubP protein (Yamaichi et al., 2012), thereby setting the subcellular position for assembly of the replication machinery. In contrast, the origin (oriII) of the second, smaller chromosome (chrII) is located at mid-cell. Replication of $V$. cholerae chrII starts later than that of chrl to synchronize the termination of replication of both chromosomes (Demarre et al., 2014; Ramachandran et al., 2018). As a result of the subpolar localization of C. crescentus and $V$. cholerae (chrI) replisomes near the old cell pole, one of the newly replicated oriC regions travels across the chromosome to the opposite cell pole with the assistance of the ParABS system (Toro et al., 2008; Ramachandran et al., 2014). Interestingly, in $P$. aeruginosa exhibiting ori-ter orientation, the chromosome is apparently not anchored to the cell pole, as shown by the cytoplasmic gap between oriC and the cell pole (Vallet-Gely and Boccard, 2013).

The multiploid and apically growing bacterial species S. coelicolor, exhibits another mode of spatiotemporal replisome localization, in which replication is initiated during vegetative growth (Figure 3D; Kois-Ostrowska et al., 2016). Replication of multiple copies of the $S$. coelicolor chromosome starts asynchronously, and newly replicated sister chromosomes follow the extending hyphal tip. Similar to Mycobacterium, positioning of the tip-proximal oriC (and hence the replisomes) is maintained through ParA interactions with the polarisome complex, which includes the proteins ParB, DivIVA, and Scy (Flärdh et al., 2012; Ditkowski et al., 2013). In the closely related and diploid species C. glutamicum, replisomes are assembled on each chromosome asymmetrically, in proximity to the cell poles (Figure 3D; Böhm et al., 2017). Fluorescently tagged ParB attaches to the cell poles, suggesting an ori-ter-ter-ori spatial orientation of C. glutamicum chromosomes.

Described differences among bacteria in the positioning of oriC regions during the replication initiation reflect the different modes of chromosome segregation. Mid-cell replisomes location results in symmetric segregation of oriCs toward the opposite cell poles, while polar and offcenter replisome positioning imply asymmetric segregation of the newly replicated oriC regions. Furthermore, polar localization requires the complex system to either anchor oriC directly at the pole (e.g., PopZ and HubP proteins) or to maintain the subpolar position by protein complexes (e.g., the interaction of ParABS system with the DivIVA or the BacNOP). Such variety in the composition of multiprotein complexes involved in oriC(s) positioning provides an opportunity for the discovery of novel genus/species-specific drug targets.

\section{CONCLUSION}

Single-cell fluorescence imaging and fluorescence tagging techniques allow researchers to precisely visualize proteins and their complexes inside living bacterial cells in real time. These techniques revealed that many proteins are targeted to distinct subcellular positions, where they participate in various cellular processes including chromosome replication. Recent studies using advanced live-cell imaging demonstrated that chromosome replication is coordinated with other key steps of the cell cycle, such as chromosome segregation and cell division. Proteins (or protein complexes) involved in condensation (i.e., SMC/MukB), chromosome segregation (i.e., ParAB in Gram-negative and Gram-positive bacteria) and/or cell division (DivIVA in Gram-positive bacteria) take part directly or indirectly in oriC positioning, thus indicating the site of replisome assembly. Additionally, other proteins guiding the oriC region have been recently identified. Interestingly, they vary significantly among different bacteria, e.g., PopZ (C. crescents), HubP (V. cholerae, chromosome I), and bactofilins (M. xanthus). The diversity and complexity of the systems involved in oriC (and thus replisome) subcellular positioning suggest the possibility of developing new antimicrobial therapies and/or altering existing treatments (Kaguni, 2018).

\section{AUTHOR CONTRIBUTIONS}

All authors listed have made a substantial, direct, and intellectual contribution to the work, and approved it for publication.

\section{FUNDING}

This study was supported by the National Science Center, Poland (MAESTRO Grant 2012/04/A/NZ1/00057 and OPUS Grant 2017/25/B/NZ1/00657). The cost of publication was supported by the Wrocław Centre of Biotechnology under the Leading National Research Centre (KNOW) program, 2014-2018.

\section{ACKNOWLEDGMENTS}

We apologize that numerous original papers could not be cited due to space limitations. 


\section{REFERENCES}

Arias-Cartin, R., Dobihal, G. S., Campos, M., Surovtsev, I. V., Parry, B., and JacobsWagner, C. (2017). Replication fork passage drives asymmetric dynamics of a critical nucleoid-associated protein in Caulobacter. EMBO J. 36, 301-318. doi: $10.15252 / \mathrm{embj} .201695513$

Aves, S. J. (2009). DNA replication initiation. Methods Mol. Biol. Clifton NJ 521, 3-17. doi: 10.1007/978-1-60327-815-7_1

Bach, T., Morigen, and Skarstad, K. (2008). The initiator protein DnaA contributes to keeping new origins inactivated by promoting the presence of hemimethylated DNA. J. Mol. Biol. 384, 1076-1085. doi: 10.1016/j.jmb.2008.09. 042

Badrinarayanan, A., Le, T. B. K., and Laub, M. T. (2015). Bacterial chromosome organization and segregation. Annu. Rev. Cell Dev. Biol. 31, 171-199. doi: 10.1146/annurev-cellbio-100814-125211

Bates, D., and Kleckner, N. (2005). Chromosome and replisome dynamics in E. coli: loss of sister cohesion triggers global chromosome movement and mediates chromosome segregation. Cell 121, 899-911. doi: 10.1016/j.cell.2005.04.013

Beattie, T. R., Kapadia, N., Nicolas, E., Uphoff, S., Wollman, A. J., Leake, M. C., et al. (2017). Frequent exchange of the DNA polymerase during bacterial chromosome replication. eLife 6:e21763. doi: 10.7554/eLife.21763

Berkmen, M. B., and Grossman, A. D. (2006). Spatial and temporal organization of the Bacillus subtilis replication cycle. Mol. Microbiol. 62, 57-71. doi: 10.1111/j. 1365-2958.2006.05356.x

Bird, R. E., Louarn, J., Martuscelli, J., and Caro, L. (1972). Origin and sequence of chromosome replication in Escherichia coli. J. Mol. Biol. 70, 549-566. doi: 10.1016/0022-2836(72)90559-1

Boccard, F., Esnault, E., and Valens, M. (2005). Spatial arrangement and macrodomain organization of bacterial chromosomes. Mol. Microbiol. 57, 9-16. doi: 10.1111/j.1365-2958.2005.04651.x

Böhm, K., Meyer, F., Rhomberg, A., Kalinowski, J., Donovan, C., and Bramkamp, M. (2017). Novel chromosome organization pattern in actinomycetales-overlapping replication cycles combined with diploidy. mBio 8:e00511-17. doi: 10.1128/mBio.00511-17

Bowman, G. R., Comolli, L. R., Zhu, J., Eckart, M., Koenig, M., Downing, K. H., et al. (2008). A polymeric protein anchors the chromosomal origin/ParB complex at a bacterial cell pole. Cell 134, 945-955. doi: 10.1016/j.cell.2008.07. 015

Cattoni, D. I., Fiche, J.-B., Valeri, A., Mignot, T., and Nöllmann, M. (2013). Superresolution imaging of bacteria in a microfluidics device. PLoS One 8:e76268. doi: 10.1371 /journal.pone.0076268

Costantini, L. M., Fossati, M., Francolini, M., and Snapp, E. L. (2012). Assessing the tendency of fluorescent proteins to oligomerize under physiologic conditions. Traffic Cph. Den. 13, 643-649. doi: 10.1111/j.1600-0854.2012. 01336.x

Danilova, O., Reyes-Lamothe, R., Pinskaya, M., Sherratt, D., and Possoz, C. (2007). MukB colocalizes with the oriC region and is required for organization of the two Escherichia coli chromosome arms into separate cell halves. Mol. Microbiol. 65, 1485-1492. doi: 10.1111/j.1365-2958.2007.05881.x

Demarre, G., Galli, E., Muresan, L., Paly, E., David, A., Possoz, C., et al. (2014). Differential management of the replication terminus regions of the two Vibrio cholerae chromosomes during cell division. PLoS Genet. 10:e1004557. doi: 10. 1371/journal.pgen.1004557

Dhar, N., and Manina, G. (2015). Single-cell analysis of mycobacteria using microfluidics and time-lapse microscopy. Methods Mol. Biol. Clifton NJ 1285, 241-256. doi: 10.1007/978-1-4939-2450-9_14

Ditkowski, B., Holmes, N., Rydzak, J., Donczew, M., Bezulska, M., Ginda, K., et al. (2013). Dynamic interplay of ParA with the polarity protein, Scy, coordinates the growth with chromosome segregation in Streptomyces coelicolor. Open Biol. 3:130006. doi: 10.1098/rsob.130006

Donczew, M., Mackiewicz, P., Wróbel, A., Flärdh, K., ZakrzewskaCzerwińska, J., and Jakimowicz, D. (2016). ParA and ParB coordinate chromosome segregation with cell elongation and division during Streptomyces sporulation. Open Biol. 6:150263. doi: 10.1098/rsob.15 0263

Donczew, R., Weigel, C., Lurz, R., Zakrzewska-Czerwińska, J., and ZawilakPawlik, A. (2012). Helicobacter pylori oriC-the first bipartite origin of chromosome replication in gram-negative bacteria. Nucleic Acids Res. 40, 9647-9660. doi: 10.1093/nar/gks742

Donovan, C., Schwaiger, A., Krämer, R., and Bramkamp, M. (2010). Subcellular localization and characterization of the ParAB system from Corynebacterium glutamicum. J. Bacteriol. 192, 3441-3451. doi: 10.1128/JB.00214-10

Fernandez-Fernandez, C., Grosse, K., Sourjik, V., and Collier, J. (2013). The $\beta$-sliding clamp directs the localization of $\mathrm{HdaA}$ to the replisome in Caulobacter crescentus. Microbiology 159, 2237-2248. doi: 10.1099/mic.0.068577-0

Flärdh, K., Richards, D. M., Hempel, A. M., Howard, M., and Buttner, M. J. (2012). Regulation of apical growth and hyphal branching in Streptomyces. Curr. Opin. Microbiol. 15, 737-743. doi: 10.1016/j.mib.2012.10.012

Fogel, M. A., and Waldor, M. K. (2005). Distinct segregation dynamics of the two Vibrio cholerae chromosomes. Mol. Microbiol. 55, 125-136. doi: 10.1111/j.13652958.2004.04379.x

Fossum, S., Crooke, E., and Skarstad, K. (2007). Organization of sister origins and replisomes during multifork DNA replication in Escherichia coli. EMBO J. 26, 4514-4522. doi: 10.1038/sj.emboj.7601871

Frunzke, J., Bramkamp, M., Schweitzer, J.-E., and Bott, M. (2008). Population heterogeneity in Corynebacterium glutamicum ATCC 13032 caused by prophage CGP3. J. Bacteriol. 190, 5111-5119. doi: 10.1128/JB.00310-08

Gao, F., and Zhang, C.-T. (2008). Ori-Finder: a web-based system for finding oriCs in unannotated bacterial genomes. BMC Bioinformatics 9:79. doi: 10.1186/14712105-9-79

Georgescu, R. E., Kurth, I., and O’Donnell, M. E. (2012). Single-molecule studies reveal the function of a third polymerase in the replisome. Nat. Struct. Mol. Biol. 19, 113-116. doi: 10.1038/nsmb.2179

Ginda, K., Bezulska, M., Ziółkiewicz, M., Dziadek, J., Zakrzewska-Czerwińska, J., and Jakimowicz, D. (2013). ParA of Mycobacterium smegmatis co-ordinates chromosome segregation with the cell cycle and interacts with the polar growth determinant DivIVA. Mol. Microbiol. 87, 998-1012. doi: 10.1111/mmi.12146

Ginda, K., Santi, I., Bousbaine, D., Zakrzewska-Czerwińska, J., Jakimowicz, D., and McKinney, J. (2017). The studies of ParA and ParB dynamics reveal asymmetry of chromosome segregation in Mycobacteria. Mol. Microbiol. 105, 453-468. doi: $10.1111 / \mathrm{mmi} .13712$

Gruber, S., and Errington, J. (2009). Recruitment of condensin to replication origin regions by $\mathrm{ParB} / \mathrm{SpoOJ}$ promotes chromosome segregation in B. subtilis. Cell 137, 685-696. doi: 10.1016/j.cell.2009.02.035

HaloTag ${ }^{\circledR}$ Protein Purification System (2018). HaloTag Protein Purification System. Available at: https://pl.promega.com/products/protein-purification/proteinpurification-kits/halotag-protein-purification-system/ [Accessed September $28,2018]$.

Harms, A., Treuner-Lange, A., Schumacher, D., and Søgaard-Andersen, L. (2013). Tracking of chromosome and replisome dynamics in Myxococcus xanthus reveals a novel chromosome arrangement. PLoS Genet. 9:e1003802. doi: 10. 1371/journal.pgen.1003802

Hołówka, J., Trojanowski, D., Janczak, M., Jakimowicz, D., and ZakrzewskaCzerwińska, J. (2018). The origin of chromosomal replication is asymmetrically positioned on the mycobacterial nucleoid, and the timing of its firing depends on HupB. J. Bacteriol. 200:e00044-18. doi: 10.1128/JB.00044-18

Jaworski, P., Donczew, R., Mielke, T., Weigel, C., Stingl, K., and Zawilak-Pawlik, A. (2018). Structure and function of the Campylobacter jejuni chromosome replication origin. Front. Microbiol. 9:1533. doi: 10.3389/fmicb.2018.01533

Jensen, R. B., Wang, S. C., and Shapiro, L. (2001). A moving DNA replication factory in Caulobacter crescentus. EMBO J. 20, 4952-4963. doi: 10.1093/emboj/ 20.17.4952

Joyce, G., Robertson, B. D., and Williams, K. J. (2011). A modified agar pad method for mycobacterial live-cell imaging. BMC Res. Notes 4:73. doi: 10.1186/17560500-4-73

Kaguni, J. M. (2018). The macromolecular machines that duplicate the Escherichia coli chromosome as targets for drug discovery. Antibiot. Basel Switz. 7:E23. doi: 10.3390/antibiotics7010023

Kaguni, J. M., and Kornberg, A. (1984). Replication initiated at the origin (oriC) of the E. coli chromosome reconstituted with purified enzymes. Cell 38, 183-190. doi: 10.1016/0092-8674(84)90539-7

Katayama, T. (2017). Initiation of DNA replication at the chromosomal origin of E. coli, oriC. Adv. Exp. Med. Biol. 1042, 79-98. doi: 10.1007/978-981-10-6955-0_4 
Kjos, M., and Veening, J.-W. (2014). Tracking of chromosome dynamics in live Streptococcus pneumoniae reveals that transcription promotes chromosome segregation. Mol. Microbiol. 91, 1088-1105. doi: 10.1111/mmi.12517

Kois-Ostrowska, A., Strzałka, A., Lipietta, N., Tilley, E., ZakrzewskaCzerwińska, J., Herron, P., et al. (2016). Unique function of the bacterial chromosome segregation machinery in apically growing streptomyces Targeting the chromosome to new hyphal tubes and its anchorage at the tips. PLoS Genet. 12:e1006488. doi: 10.1371/journal.pgen.100 6488

Kongsuwan, K., Dalrymple, B. P., Wijffels, G., and Jennings, P. A. (2002). Cellular localisation of the clamp protein during DNA replication. FEMS Microbiol. Lett. 216, 255-262. doi: 10.1111/j.1574-6968.2002.tb11444.x

Laloux, G., and Jacobs-Wagner, C. (2013). Spatiotemporal control of PopZ localization through cell cycle-coupled multimerization. J. Cell Biol. 201, 827841. doi: 10.1083/jcb.201303036

Landete, J. M., Langa, S., Revilla, C., Margolles, A., Medina, M., and Arqués, J. L. (2015). Use of anaerobic green fluorescent protein versus green fluorescent protein as reporter in lactic acid bacteria. Appl. Microbiol. Biotechnol. 99, 6865-6877. doi: 10.1007/s00253-015-6770-3

Lau, I. F., Filipe, S. R., Søballe, B., Økstad, O.-A., Barre, F.-X., and Sherratt, D. J. (2003). Spatial and temporal organization of replicating Escherichia coli chromosomes. Mol. Microbiol. 49, 731-743. doi: 10.1046/j.1365-2958.2003. 03640.x

Le, T. B., and Laub, M. T. (2014). New approaches to understanding the spatial organization of bacterial genomes. Curr. Opin. Microbiol. 22, 15-21. doi: 10 . 1016/j.mib.2014.09.014

Lemon, K. P., and Grossman, A. D. (1998). Localization of bacterial DNA polymerase: evidence for a factory model of replication. Science 282, 1516-1519. doi: $10.1126 /$ science.282.5393.1516

Lemon, K. P., and Grossman, A. D. (2000). Movement of replicating DNA through a stationary replisome. Mol. Cell 6, 1321-1330. doi: 10.1016/S1097-2765(00) 00130- 1

Leonard, A. C., and Grimwade, J. E. (2011). Regulation of DnaA assembly and activity: taking directions from the genome. Annu. Rev. Microbiol. 65, 19-35. doi: 10.1146/annurev-micro-090110-102934

Leonard, A. C., and Grimwade, J. E. (2015). The orisome: structure and function. Front. Microbiol. 6:545. doi: 10.3389/fmicb.2015.00545

Lewis, J. S., Spenkelink, L. M., Jergic, S., Wood, E. A., Monachino, E., Horan, N. P., et al. (2017). Single-molecule visualization of fast polymerase turnover in the bacterial replisome. eLife 6:e23932. doi: 10.7554/eLife. 23932

Li, Y., Schroeder, J. W., Liao, Y., Chen, Z., Simmons, L. A., and Biteen, J. S. (2018). Super-resolution imaging of DNA replisome dynamics in live Bacillus subtilis. Biophys. J. 114:539a. doi: 10.1016/j.bpj.2017.11.2942

Li, Y., Sergueev, K., and Austin, S. (2002). The segregation of the Escherichia coli origin and terminus of replication. Mol. Microbiol. 46, 985-996. doi: 10.1046/j. 1365-2958.2002.03234.x

Liao, Y., Li, Y., Schroeder, J. W., Simmons, L. A., and Biteen, J. S. (2016). Singlemolecule DNA polymerase dynamics at a bacterial replisome in live cells. Biophys. J. 111, 2562-2569. doi: 10.1016/j.bpj.2016.11.006

Lin, L., Osorio Valeriano, M., Harms, A., Søgaard-Andersen, L., and Thanbichler, M. (2017). Bactofilin-mediated organization of the ParABS chromosome segregation system in Myxococcus xanthus. Nat. Commun. 8:1817. doi: 10.1038/s41467-017-02015-Z

Lin, Y.-S., Kieser, H. M., Hopwood, D. A., and Chen, C. W. (1993). The chromosomal DNA of Streptomyces lividans 66 is linear. Mol. Microbiol. 10, 923-933. doi: 10.1111/j.1365-2958.1993.tb00964.x

Lioy, V. S., Cournac, A., Marbouty, M., Duigou, S., Mozziconacci, J., Espéli, O., et al. (2018). Multiscale structuring of the E. coli chromosome by nucleoidassociated and condensin proteins. Cell 172, 771.e18-783.e18. doi: 10.1016/j. cell.2017.12.027

Liu, X., Wang, X., Reyes-Lamothe, R., and Sherratt, D. (2010). Replication-directed sister chromosome alignment in Escherichia coli. Mol. Microbiol. 75, 1090-1097. doi: 10.1111/j.1365-2958.2009.06791.x

Livny, J., Yamaichi, Y., and Waldor, M. K. (2007). Distribution of centromere-like parS sites in bacteria: insights from comparative genomics. J. Bacteriol. 189, 8693-8703. doi: 10.1128/JB.01239-07
Makowski, E, Donczew, R., Weigel, C., Zawilak-Pawlik, A., and ZakrzewskaCzerwińska, J. (2016). Initiation of chromosomal replication in predatory bacterium Bdellovibrio bacteriovorus. Front. Microbiol. 7:1898. doi: 10.3389/ fmicb.2016.01898

Mangiameli, S. M., Veit, B. T., Merrikh, H., and Wiggins, P. A. (2017). The replisomes remain spatially proximal throughout the cell cycle in bacteria. PLoS Genet. 13:e1006582. doi: 10.1371/journal.pgen.1006582

Masai, H., Matsumoto, S., You, Z., Yoshizawa-Sugata, N., and Oda, M. (2010). Eukaryotic chromosome DNA replication: where, when, and how? Annu. Rev. Biochem. 79, 89-130. doi: 10.1146/annurev.biochem.052308.103205

Méchali, M. (2010). Eukaryotic DNA replication origins: many choices for appropriate answers. Nat. Rev. Mol. Cell Biol. 11, 728-738. doi: 10.1038/ nrm 2976

Mettrick, K. A., and Grainge, I. (2016). Stability of blocked replication forks in vivo. Nucleic Acids Res. 44, 657-668. doi: 10.1093/nar/gkv1079

Midgley-Smith, S. L., Dimude, J. U., Taylor, T., Forrester, N. M., Upton, A. L., Lloyd, R. G., et al. (2018). Chromosomal over-replication in Escherichia coli recG cells is triggered by replication fork fusion and amplified if replichore symmetry is disturbed. Nucleic Acids Res. 46, 7701-7715. doi: 10.1093/nar/gky566

Migocki, M. D., Lewis, P. J., Wake, R. G., and Harry, E. J. (2004). The midcell replication factory in Bacillus subtilis is highly mobile: implications for coordinating chromosome replication with other cell cycle events. Mol. Microbiol. 54, 452-463. doi: 10.1111/j.1365-2958.2004.04267.x

Moolman, M. C., Krishnan, S. T., Kerssemakers, J. W. J., van den Berg, A., Tulinski, P., Depken, M., et al. (2014). Slow unloading leads to DNA-bound $\beta 2$ sliding clamp accumulation in live Escherichia coli cells. Nat. Commun. 5:5820. doi: $10.1038 /$ ncomms 6820

Nielsen, H. J., Ottesen, J. R., Youngren, B., Austin, S. J., and Hansen, F. G. (2006). The Escherichia coli chromosome is organized with the left and right chromosome arms in separate cell halves. Mol. Microbiol. 62, 331-338. doi: 10.1111/j.1365-2958.2006.05346.x

Nielsen, H. J., Youngren, B., Hansen, F. G., and Austin, S. (2007). Dynamics of Escherichia coli chromosome segregation during multifork replication. J. Bacteriol. 189, 8660-8666. doi: 10.1128/JB.01212-07

Nielsen, O., and Løbner-Olesen, A. (2008). Once in a lifetime: strategies for preventing re-replication in prokaryotic and eukaryotic cells. EMBO Rep. 9, 151-156. doi: 10.1038/sj.embor.2008.2

Niki, H., Imamura, R., Kitaoka, M., Yamanaka, K., Ogura, T., and Hiraga, S. (1992). E. coli MukB protein involved in chromosome partition forms a homodimer with a rod-and-hinge structure having DNA binding and ATP/GTP binding activities. EMBO J. 11, 5101-5109. doi: 10.1002/j.1460-2075.1992.tb 05617.x

Possoz, C., Filipe, S. R., Grainge, I., and Sherratt, D. J. (2006). Tracking of controlled Escherichia coli replication fork stalling and restart at repressor-bound DNA in vivo. EMBO J. 25, 2596-2604. doi: 10.1038/sj.emboj.7601155

Postow, L., Hardy, C. D., Arsuaga, J., and Cozzarelli, N. R. (2004). Topological domain structure of the Escherichia coli chromosome. Genes Dev. 18, 17661779. doi: 10.1101/gad.1207504

Raaphorst, R., van Kjos, M., and Veening, J.-W. (2017). Chromosome segregation drives division site selection in Streptococcus pneumoniae. Proc. Natl. Acad. Sci. U.S.A. 114, E5959-E5968. doi: 10.1073/pnas.1620608114

Ramachandran, R., Ciaccia, P. N., Filsuf, T. A., Jha, J. K., and Chattoraj, D. K. (2018). Chromosome 1 licenses chromosome 2 replication in Vibrio cholerae by doubling the crtS gene dosage. PLoS Genet. 14:e1007426. doi: 10.1371/journal. pgen.1007426

Ramachandran, R., Jha, J., and Chattoraj, D. (2014). Chromosome segregation in Vibrio cholerae. J. Mol. Microbiol. Biotechnol. 24, 360-370. doi: 10.1159/ 000368853

Reyes-Lamothe, R., Nicolas, E., and Sherratt, D. J. (2012). Chromosome replication and segregation in bacteria. Annu. Rev. Genet. 46, 121-143. doi: 10.1146/ annurev-genet-110711-155421

Reyes-Lamothe, R., Possoz, C., Danilova, O., and Sherratt, D. J. (2008). Independent positioning and action of Escherichia coli replisomes in live cells. Cell 133, 90-102. doi: 10.1016/j.cell.2008.01.044

Reyes-Lamothe, R., Sherratt, D. J., and Leake, M. C. (2010). Stoichiometry and architecture of active DNA replication machinery in Escherichia coli. Science 328, 498-501. doi: 10.1126/science.1185757 
Richardson, T. T., Harran, O., and Murray, H. (2016). The bacterial DnaA-trio replication origin element specifies single-stranded DNA initiator binding. Nature 534, 412-416. doi: 10.1038/nature17962

Ruban-Ośmiałowska, B., Jakimowicz, D., Smulczyk-Krawczyszyn, A., Chater, K. F., and Zakrzewska-Czerwińska, J. (2006). Replisome localization in vegetative and aerial hyphae of Streptomyces coelicolor. J. Bacteriol. 188, 7311-7316. doi: 10.1128/JB.00940-06

Samadpour, A. N., and Merrikh, H. (2018). DNA gyrase activity regulates DnaAdependent replication initiation in Bacillus subtilis. Mol. Microbiol. 108, 115 127. doi: $10.1111 / \mathrm{mmi} .13920$

Santi, I., Dhar, N., Bousbaine, D., Wakamoto, Y., and McKinney, J. D. (2013). Single-cell dynamics of the chromosome replication and cell division cycles in mycobacteria. Nat. Commun. 4:2470. doi: $10.1038 /$ ncomms 3470

Santi, I., and McKinney, J. D. (2015). Chromosome organization and replisome dynamics in Mycobacterium smegmatis. mBio 6:e01999-14. doi: 10.1128/mBio. 01999- 14

Shaner, N. C., Steinbach, P. A., and Tsien, R. Y. (2005). A guide to choosing fluorescent proteins. Nat. Methods 2, 905-909. doi: 10.1038/nmeth819

Skarstad, K., Baker, T. A., and Kornberg, A. (1990). Strand separation required for initiation of replication at the chromosomal origin of E. coli is facilitated by a distant RNA-DNA hybrid. EMBO J. 9, 2341-2348. doi: 10.1002/j.1460-2075. 1990.tb07406.x

Skarstad, K., Boye, E., and Steen, H. B. (1986). Timing of initiation of chromosome replication in individual Escherichia coli cells. EMBO J. 5, 1711-1717. doi: 10.1002/j.1460-2075.1986.tb04415.x

Skarstad, K., and Katayama, T. (2013). Regulating DNA replication in bacteria. Cold Spring Harb. Perspect. Biol. 5:a012922. doi: 10.1101/cshperspect.a012922

Srivastava, P., and Chattoraj, D. K. (2007). Selective chromosome amplification in Vibrio cholerae. Mol. Microbiol. 66, 1016-1028. doi: 10.1111/j.1365-2958.2007. 05973.x

Stokke, C., Waldminghaus, T., and Skarstad, K. (2011). Replication patterns and organization of replication forks in Vibrio cholerae. Microbiology 157, 695-708. doi: 10.1099/mic.0.045112-0

Stracy, M., Uphoff, S., Garza de Leon, F., and Kapanidis, A. N. (2014). In vivo single-molecule imaging of bacterial DNA replication, transcription, and repair. FEBS Lett. 588, 3585-3594. doi: 10.1016/j.febslet.2014.05.026

Su'etsugu, M., and Errington, J. (2011). The replicase sliding clamp dynamically accumulates behind progressing replication forks in Bacillus subtilis cells. Mol. Cell 41, 720-732. doi: 10.1016/j.molcel.2011.02.024

Sukumar, N., Tan, S., Aldridge, B. B., and Russell, D. G. (2014). Exploitation of Mycobacterium tuberculosis reporter strains to probe the impact of vaccination at sites of infection. PLoS Pathog. 10:e1004394. doi: 10.1371/journal.ppat. 1004394

Sullivan, N. L., Marquis, K. A., and Rudner, D. Z. (2009). Recruitment of SMC by ParB-parS organizes the origin region and promotes efficient chromosome segregation. Cell 137, 697-707. doi: 10.1016/j.cell.2009.04.044

Toro, E., Hong, S.-H., McAdams, H. H., and Shapiro, L. (2008). Caulobacter requires a dedicated mechanism to initiate chromosome segregation. Proc. Natl. Acad. Sci. U.S.A. 105, 15435-15440. doi: 10.1073/pnas.0807448105

Trojanowski, D., Ginda, K., Pióro, M., Hołówka, J., Skut, P., Jakimowicz, D., et al. (2015). Choreography of the Mycobacterium replication machinery during the cell cycle. mBio 6:e02125-14. doi: 10.1128/mBio.02125-14

Trojanowski, D., Hołówka, J., Ginda, K., Jakimowicz, D., and ZakrzewskaCzerwińska, J. (2017). Multifork chromosome replication in slow-growing bacteria. Sci. Rep. 7:43836. doi: 10.1038/srep43836

Trucksis, M., Michalski, J., Deng, Y. K., and Kaper, J. B. (1998). The Vibrio cholerae genome contains two unique circular chromosomes. Proc. Natl. Acad. Sci. U.S.A. 95, 14464-14469. doi: 10.1073/pnas.95.24.14464

Valens, M., Penaud, S., Rossignol, M., Cornet, F., and Boccard, F. (2004). Macrodomain organization of the Escherichia coli chromosome. EMBO J. 23, 4330-4341. doi: 10.1038/sj.emboj.7600434
Vallet-Gely, I., and Boccard, F. (2013). Chromosomal organization and segregation in Pseudomonas aeruginosa. PLoS Genet. 9:e1003492. doi: 10.1371/journal.pgen. 1003492

van Raaphorst, R., Kjos, M., and Veening, J.-W. (2017). Chromosome segregation drives division site selection in Streptococcus pneumoniae. Proc. Natl. Acad. Sci. U.S.A. 114, E5959-E5968. doi: 10.1073/pnas.1620608114

Viollier, P. H., Thanbichler, M., McGrath, P. T., West, L., Meewan, M., McAdams, H. H., et al. (2004). Rapid and sequential movement of individual chromosomal loci to specific subcellular locations during bacterial DNA replication. Proc. Natl. Acad. Sci. U.S.A. 101, 9257-9262. doi: 10.1073/pnas.0402606101

Wallden, M., Fange, D., Lundius, E. G., Baltekin, Ö., and Elf, J. (2016). The synchronization of replication and division cycles in individual E. coli cells. Cell 166, 729-739. doi: 10.1016/j.cell.2016.06.052

Wang, P., Robert, L., Pelletier, J., Dang, W. L., Taddei, F., Wright, A., et al. (2010). Robust growth of Escherichia coli. Curr. Biol. CB 20, 1099-1103. doi: 10.1016/j. cub.2010.04.045

Wang, X., Lesterlin, C., Reyes-Lamothe, R., Ball, G., and Sherratt, D. J. (2011). Replication and segregation of an Escherichia coli chromosome with two replication origins. Proc. Natl. Acad. Sci. U.S.A. 108, E243-E250. doi: 10.1073/ pnas. 1100874108

Wang, X., Montero Llopis, P., and Rudner, D. Z. (2014). Bacillus subtilis chromosome organization oscillates between two distinct patterns. Proc. Natl. Acad. Sci. U.S.A. 111, 12877-12882. doi: 10.1073/pnas.14074 61111

Wang, X., and Rudner, D. Z. (2014). Spatial organization of bacterial chromosomes. Curr. Opin. Microbiol. 22, 66-72. doi: 10.1016/j.mib.2014. 09.016

Wang, X., and Sherratt, D. J. (2010). Independent segregation of the two arms of the Escherichia coli ori region requires neither RNA synthesis nor MreB dynamics. J. Bacteriol. 192, 6143-6153. doi: 10.1128/JB.00861-10

Winterstein, C., and Ludwig, B. (1998). Genes coding for respiratory complexes map on all three chromosomes of the Paracoccus denitrificans genome. Arch. Microbiol. 169, 275-281. doi: 10.1007/s002030050572

Wolański, M., Donczew, R., Zawilak-Pawlik, A., and Zakrzewska-Czerwińska, J. (2014). oriC-encoded instructions for the initiation of bacterial chromosome replication. Front. Microbiol. 5:735. doi: 10.3389/fmicb.2014. 00735

Wolański, M., Wali, R., Tilley, E., Jakimowicz, D., Zakrzewska-Czerwińska, J., and Herron, P. (2011). Replisome trafficking in growing vegetative hyphae of Streptomyces coelicolor A3(2). J. Bacteriol. 193, 1273-1275. doi: 10.1128/JB. 01326- 10

Yamaichi, Y., Bruckner, R., Ringgaard, S., Möll, A., Cameron, D. E., Briegel, A., et al. (2012). A multidomain hub anchors the chromosome segregation and chemotactic machinery to the bacterial pole. Genes Dev. 26, 2348-2360. doi: 10.1101/gad.199869.112

Youngren, B., Radnedge, L., Hu, P., Garcia, E., and Austin, S. (2000). A plasmid partition system of the P1-P7par family from the pMT1 virulence plasmid of Yersinia pestis. J. Bacteriol. 182, 3924-3928. doi: 10.1128/JB.182.14.3924-3928. 2000

Conflict of Interest Statement: The authors declare that the research was conducted in the absence of any commercial or financial relationships that could be construed as a potential conflict of interest.

Copyright (C) 2018 Trojanowski, Hołówka and Zakrzewska-Czerwińska. This is an open-access article distributed under the terms of the Creative Commons Attribution License (CC BY). The use, distribution or reproduction in other forums is permitted, provided the original author(s) and the copyright owner(s) are credited and that the original publication in this journal is cited, in accordance with accepted academic practice. No use, distribution or reproduction is permitted which does not comply with these terms. 